the social determinants of ill health, and we need the help of the Office of Population Censuses and Surveys, just as much as the Victorians needed its forerunner's help 150 years ago.

TONY DELAMOTHE

Assistant editor, $B M F$

1 General Register Office. Quarterly retum. London: HMSO, 1849.

2 Office of Population Censuses and Surveys. Occupational mortality. Decennial supplement England and Wales 1970-2. London: HMSO, 1978.

3 Department of Health and Social Security. Inequalities in health: report of a research working group. London: DHSS, 1980. (Black report.)

4 Baldwin JA, Acheson ED, Graham WJ, eds. Textbook of medical record linkage. Oxford: Oxford University Press, 1978:8.

5 Thatcher M. Parliamentary written answer. House of Commons Official Report (Hansard) 1986 November 16;105:col 86. (No 5.)

6 Office of Population Censuses and Surveys. Occupational mortality. Decennial supplement Great Britain 1979-80, 1982-83. London: HMSO, 1986.

7 Anonymous. Lies, damned lies, and suppressed statistics. Br Med $\mathrm{f}$ 1986;293:349-50.

8 Office of Population Censuses and Surveys. Cancer incidence and mortality in the vicinity of nuclear installations, England and Wales, 1959-1980. London: HMSO, 1987.

\section{Measles must go and with it rubella}

In Britain the public and many doctors still fail to realise the importance of preventing measles by vaccination. Perhaps the message that among the $90000-100000$ cases notified each year $10 \%$ of patients experience complications ${ }^{1}$ is insufficiently emphasised. Each year about $90-100$ patients develop measles induced encephalitis, of whom $15 \%$ die and $25 \%$ have residual sequelae. ${ }^{2}$

Measles often kills children with malignant disease, which is unnecessary and tragic as over $60 \%$ of children with acute lymphoblastic leukaemia now survive free from disease for at least five years. ${ }^{3}$ Infection, particularly measles, is responsible for the deaths of most who succumb during remission from disease not associated with leukaemia. Two studies, one from Newcastle ( $p$ 15) and the other from four centres ( $p$ 19), emphasise the severity of measles in children with malignant disease, mostly acute lymphatic leukaemia. Both draw attention to the high mortality and the difficulty in establishing a clinical diagnosis as the rash may be absent, mild, or atypical. In the four centre study measles killed a third of 51 children who died in first remission; indeed, 15 of 18 children who developed measles died. In contrast, fewer (27\%) died in the Newcastle study, probably because the authors used a rapid and sensitive immunofluorescence technique for early diagnosis; they probably identified patients with milder disease, many of whom survived. Normal human immunoglobulin usually prevents or attenuates measles if given within 72 hours of contact. Although only one of six children given this preparation died in Newcastle, it is disquieting that the four centre study reported three deaths despite normal human immunoglobulin being given promptly.

Most children develop acute lymphoblastic leukaemia after the age at which measles vaccination should have been given. Children who are still susceptible to measles after developing malignant disease cannot be given live vaccines. It is possible, however, that the further attenuated measles vaccines that are now in general use might be well tolerated by patients in remission from acute lymphoblastic leukaemia; an attenuated vaccine protects such patients from chickenpox. ${ }^{4}$ Japanese workers have shown that one of their attenuated measles vaccines (CAM70) is well tolerated and induces persistent antibody responses in children in remission from acute lymphoblastic leukaemia, but only a few patients were vaccinated and no evidence was available on protective efficacy. ${ }^{5}$ In the United States a few children and young adults with asymptomatic infection with human immunodeficiency virus (HIV) have received live vaccines without any adverse outcome, but these patients were probably less immunocompromised than children who have recently been treated for acute lymphoblastic leukaemia. The United States advisory committee on immunisation practices recommends that asymptomatic children infected with HIV may be vaccinated with a combined measles, mumps, and rubella vaccine. ${ }^{67}$

None of the patients who developed measles in the Newcastle study had a history of naturally acquired measles or measles vaccination, but three patients with fatal measles in the four centre study had had naturally acquired measles or measles vaccination. In the United States there is practically no opportunity for children with leukaemia to be exposed to measles. Legislation ensures that children are vaccinated against measles, rubella, polio, and diphtheria before entering school in all states, and for tetanus, pertussis, and mumps in most states. ${ }^{8}$ Thus in the United States almost all children will have been vaccinated against measles before developing leukaemia. Since 1971 measles vaccine has been given successfully with mumps and rubella vaccines as a combined vaccine. Measles, mumps, and rubella are now rare in the United States: about $1500-6000$ cases of measles are notified each year, most in children of preschool age living in deprived urban areas.

Any doubt about the long term efficacy of measles vaccine should be dispelled by the results of the 21 year follow up of the Medical Research Council's measles vaccine trial: those vaccinated have maintained a high order of protection compared with those not vaccinated ( $p$ 22). A few cases of measles were reported among those vaccinated: some may have been incorrectly diagnosed and others the result of vaccine failure. Vaccine stabilisers will, however, make vaccine failure very rare in future.

The rate of uptake of measles vaccine among infants in England and Wales is now $68 \%$, which is comparable with the uptake rate for pertussis vaccine but well below the $85 \%$ for diphtheria, pertussis, and tetanus (DPT) and polio, vaccines. In many districts, not all in urban deprived areas, the proportion is well below $68 \%$. In contrast, some districts with high unemployment rates, such as north west Durham and Bolton, have vaccinated $75-80 \%$ of infants against measles (M T Begg, personal communication). Can Britain without legislation meet the World Health Organisation's target in Europe of a $90 \%$ uptake rate for DPT, tetanus, polio, rubella, and measles vaccines?" The aim is to eradicate these diseases by the year 2000. Many European countries, including the Netherlands and Nordic countries, are already approaching this target without having to resort to compulsion. (World Health Organisation European Advisory Group circulated report on expanded programme of immunisation, 1986.)

In an attempt to achieve this goal the Department of Health and Social Security has now asked each health district to nominate a person responsible for its immunisation performance. District health authorities will be accountable through the review system for their performance. The National Health Service Management Board should also take an active interest in improving immunisation rates. It was 
encouraging that 150 duly appointed officers from the 201 health districts in England and Wales attended a meeting in London on World Health Day. Future meetings aimed at identifying problems, methods by which they may be overcome, and exchange of ideas are planned. But success will largely be dependant on the commitment, enthusiasm, and drive of the appointed officers, many of whom are specialists in community medicine. They are busy people; will they have sufficient time to devote to improving their district's immunisation performance?

On World Health Day the chief medical officer announced that combined measles, mumps, and rubella vaccine will shortly be introduced in Britain for immunising children of both sexes in their second year of life. The aim of inducing rubella as well as measles and mumps immunity among preschool children of both sexes is to eliminate the hazard of pregnant women being infected by young children, often their own. This procedure will augment rubella vaccination of schoolgirls and susceptible adult women. An $86 \%$ uptake rate of rubella vaccination among 10-14 year old schoolgirls has now been achieved in England and Wales, and a recent study showed that only $2 \cdot 8 \%$ of 72200 pregnant women were susceptible to rubella compared with $8.5 \%$ of men in the same age group. ${ }^{10}$ Although current vaccination policy directed towards schoolgirls and rubella susceptible adult women is resulting in a considerable decrease in maternal rubella, complete vaccination of the target population is almost certainly an unrealistic goal, but vaccination of a high proportion of young children will drastically reduce the circulation of rubella virus in the community. Currently, susceptible pregnant women continue to acquire rubella: 173 cases of laboratory confirmed rubella occurring during the first 16 weeks of pregnancy were reported in 1986. ${ }^{11}$ In addition to the anxiety of patients and those caring for them, considerable resources continue to be expended by laboratory investigations.

The augmented rubella vaccination policy will eventually require a "catch up" programme so that children aged 2-10 may also be protected against measles, mumps, and rubella. Incorporating rubella and mumps vaccine with measles will probably increase measles uptake rates, as occurred in Sweden. ${ }^{12}$ The Public Health Laboratory Service is already monitoring this programme by examining the prevalence of antibodies to measles, mumps, and rubella in different age groups.

Although the augmented programme is designed eventually to eradicate infection, the United States experience suggests that it may be more difficult to achieve than had been expected. Studies with mathematical models show that poor vaccination uptake rates in preschool children may increase the proportion susceptible to rubella among older age groups. ${ }^{1314}$ This caveat should not be a reason for discouraging the augmented programme but rather an incentive for ensuring that high uptake rates are obtained.

Although there may be an increased risk of mumps in adults, in whom complications such as orchitis are more likely to occur if vaccine uptake rates are poor, in the United States the combined vaccine has resulted in a decrease of $95 \%$ in the incidence of mumps from the prevaccination era. ${ }^{\text {is }}$ There has been no increase in the incidence of mumps among adults.

Professor of Virology,

J E Banatvala

St Thomas's Campus,

United Medical and Dental Schools of

Guy's and St Thomas's Hospitals, London SE1 7EH
1 Miller CL. Severity of notified measles. Br Med f 1978;i:1253.

Centres for Disease Control. Measles encephalitis-United States 1962-1979. MMWR 1981;30. $362-4$.

3 Mauer AM. New direction in the treatment of acute lymphoblastic leukemia in children. $N$ Engl $\}$ Med 1986;315:316-7.

4 André F, Heath RB, Malpas J, eds. Proceedings of a Symposium, Munich 1984. Active immunization against varicella. Postgrad Med J 1985;61(suppl 4):7-108S.

Torigoe S, Hirai S, Oitani K, et al. Application of live attenuated measles and mumps vaccine in children with acute leukemia. Biken f 1981;24:147-51.

6 Centers for Disease Control. Immunization of children infected with human T-lymphotropicassociated virus type III/lymphadenopathy-associated virus. MMWR 1986;36:595-606.

7 US Advisory Committee on Immunization Practices. Immunization of children infected with human T-lymphotropic-associated virus type III/lymphadenopathy-associated virus. Ann human T-lymphotropic-assoc.

8 Centers for Disease Control. State immunization requirements 1985-86. Washington, DC: US Department of Health and Human Sciences, Public Health Services, 1986.

World Health Organisation. Expanded programme on immunization. Weekly Epidemiological Record 1985;22:165-8.

10 Miller CL, Miller E. Rubella vaccination in the UK: time for a complete strategy. Lancet 1985;ii:732.

11 Miller CL, Miller E, Waight PA. Rubella susceptibility and the continuing risk of infection in pregnancy. Br Med f 1987;294:1277-8.

2 Best JM, Welch JM, Baker DA, Banatvala JE. Maternal rubella at St Thomas' Hospital in 1978 and 1986-support for augmenting the rubella vaccination programme. Lancet (in press)

13 Rabo E, Taranger J. Scandinavian model for eliminating measles, mumps, and rubella. Br Med $\mathcal{f}$ 1984;289:1402-4.

14 Knox EG. Evaluation of rubella vaccine policy for the UK. Int $\mathcal{E}$ Epidemiol (in press).

15 Anderson RM, May RM. Vaccination against rubella and measles: quantitative investigations of different policies. $\mathcal{J}$ Hyg (Camb) 1983;90:259-325.

16 Centers for Disease Control. Mumps-United States 1985-1986. MMWR 1987;36:151-5.

\section{Lymphoedema of the arm}

Lymphoedema of the arm is rare. Most cases are caused by disease in the axillary and subclavian lymph nodes or by their surgical or radiotherapeutic destruction. Of the 2000 patients with primary lymphoedema we have seen at St Thomas's Hospital in the past 30 years, only 16 have had primary lymphoedema of the arm. ${ }^{1}$ In nearly all of them the condition was associated with oedema of the legs and was congenital; it presented at or soon after birth and on lymphography was shown to be due to obliteration of the lymphatics. ${ }^{2}$ In the arm we have not seen enlarged lymphatics (the so called megalymphatics), as may occur elsewhere in the body. Nor have we seen a patient with primary lymphoedema severe enough to warrant surgical intervention; in every case an elastic arm stocking and pneumatic compression have been sufficient to keep the limb to a manageable and functionally useful size.

Conversely, in the same period in the many more patients with secondary lymphoedema the condition has often been severe enough for us to consider surgery. Secondary lymphoedema of the arm occurs most commonly after mastectomy. Oedema caused by primary disease of the lymph nodes affecting the axillary or subclavian nodes often improves when these are treated with irradiation, but oedema caused by neoplastic infiltration, surgical excision, or radiotherapeutic destruction of the axillary lymph nodes invariably progresses.

The incidence of oedema of the arm after mastectomy varies according to the method of assessment. Kissin et al have suggested that a difference in the volume of the arm, measured between the tips of the fingers and a point $15 \mathrm{~cm}$ above the lateral epicondyle, that is over $200 \mathrm{ml}$ is diagnostic of arm oedema and occurs after a quarter of mastectomies. ${ }^{3}$ The degree of oedema, ${ }^{3}$ and of the restriction of arm movements, ${ }^{4}$ is closely related to the damage to the lymph nodes. Thus local operations within the breast or sampling of the axillary lymph nodes rarely cause swelling of the arm; excision of the axillary nodes or radiotherapy alone causes 